Keywords: Dual diagnosis; Comorbidity; Comorbidity patterns; Severe mental illness; Substance use disorders.

\title{
Comorbidity patterns in dual diagnosis across seven European sites
}

\section{K. Charzynska* \\ E. Hyldager ${ }^{\star *}$ \\ A. Baldacchino*** \\ T. Greacen ${ }^{\star \star \star \star}$ \\ Z. Henderson ${ }^{\star \star \star \star *}$ \\ H. Laijärvi* \\ C.L. Hodges ${ }^{\star \star *}$ \\ C. Lack \\ J. Sieroslawski ${ }^{\star}$ \\ K. Baeck-Moller**}

* Institute of Psychiatry \& Neurology, Warsaw

** University Hospital of Aarhus

*** University of Dundee, Institute of Neuroscience, Dundee

**** Laboratoire de recherche, Etablissement Public de Santé Maison-Blanche, Paris

***** Middlesex University, Department of Mental Health, London

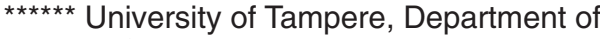
Nursing Science, Tampere

******* Cambridge University, Department of Psychiatry, Cambridge

POLAND

DENMARK

SCOTLAND

FRANCE

UNITED KINGDOM

FINLAND 
Methods: 352 patients were included consecutively from psychiatric inpatients units at 7 European sites and interviewed with the Mini- International Neuropsychiatric Interview and the European version of the Addiction Severity Index questionnaires. For analysis the psychiatric diagnostic groups were organized into broader categories.

Results: Concurrent alcohol use disorder and mood disorder was found to be the most prevalent comorbidity pattern $(30.8 \%)$ across Europe. Alcohol or drug use disorder combined with mood disorder was most prevalent among females and in the older age group whereas mixed substance use and psychosis was more frequent among males and younger participants. Finally, differences in comorbidity patterns were found at different European sites.

Conclusions: The prevalence of different comorbidity patterns varied across European clinical settings. Significant differences between comorbidity subgroups were found with regard to age and gender.

\section{Introduction}

Results from the Epidemiologic Catchment Area (ECA) project show that, compared to the general population, individuals treated in psychiatric settings have significantly higher odds of having comorbid substance use disorders ${ }^{1}$. Studies report that 20 $75 \%$ of psychiatric patients have concomitant substance use disorders ${ }^{2-5}$, with high rates specific to inpatients. Dixon et al. find that $48 \%$ of consecutively admitted psychotic inpatients received diagnoses of either drug or alcohol abuse or dependence ${ }^{6}$. Alcohol is the most frequently used substance, followed by cannabis, cocaine and hallucinogens, respectively. Polydrug use, the use of at least two substances simultaneously, is also very prevalent. Study conducted among psychiatric inpatients of a large hospital showed that approximately $30 \%$ of the patients were found to be polydrug users ${ }^{7}$.

A study of treatment seeking patients with severe mental illness in south London reports that young male subjects are at higher risk of having substance misuse prob- lems ${ }^{2,3}$. Furthermore psychiatric patients with concomitant substance use disorders are more likely to have a low educational level ${ }^{8}$, single marital status and be unemployed $^{8}$ as well as homeless ${ }^{9}$. They are also at increased risk of suicide/self harm and homicide ${ }^{10}$ and poor clinical outcome $\mathrm{e}^{11,12}$ with associated higher costs of care ${ }^{13,14}$.

Due to these grave consequences, psychiatric inpatients with substance use disorders are a significant public health concern which needs greater awareness and further investigation. Most information on prevalence and patterns of substance abuse in patients with severe mental illness is primarily derived from individual studies looking at specific study populations in North America and England. The current study explores these issues in a trans- European sample of adult psychiatric inpatients with the following two main aims:

1. To examine and compare patterns of comorbidity among inpatients in psychiatric settings across seven European sites; 
2. To examine and compare characteristics of subgroups of psychiatric inpatients with comorbid substance use disorders across these seven European sites

\section{Method}

\section{Design and setting}

The ISADORA study was designed to describe and compare comorbidity, service use of and service provision for patients with dual diagnosis (mental illness with concurrent substance abuse) in seven European psychiatric settings. Data was collected from inpatient psychiatric departments and specialized dual diagnosis inpatient wards at: Aarhus, Denmark; Paris, France; Tampere, Finland; Dundee, Scotland; Warsaw, Poland; London and Cambridge, England. Within each setting on-site psychiatrists identified potential study participants and referred them for initial screening for substance use disorders. Screening was performed by trained researchers at least 48 after admission to allow for a drug use side effects to disappear. Patients meeting inclusion criteria were informed about the study and asked to give written consent. Research ethics approval was individually obtained by study partners at their relevant local ethics committees.

\section{Material}

For the purpose of the current article data from selected parts of the Mini International Neuropsychiatric Interview (M.I.N.I., version 5.0, DSM-IV) ${ }^{15}$ and from the European Addiction Severity Index (EuropASI, European adaptation $)^{16}$ were used. M.I.N.I is a structured psychiatric interview for multicenter clinical trials and EuropASI is a semistructured instrument which covers the following areas: medical, employment/support, drug and alcohol use, legal, family/social, and psychiatric.

\section{Subjects}

A total of 352 patients consecutively admitted to inpatient psychiatric departments and specialized dual diagnosis inpatient wards were included in the study.

Table 1

Sample size (n)

\begin{tabular}{ccccccccc} 
& All sites & Aarhus & Paris & Tampere & Dundee & Warsaw & Middlesex & Cambridge \\
\hline Sample size & 352 & 50 & 50 & 52 & 50 & 50 & 50 & 50 \\
\hline
\end{tabular}

All participants were recruited from catchment area of approximately 200,000 inhabitants which was defined individually within the study setting administrative regions. The inclusion criteria specified an age range of between 18 and 65 years with an ICD-10 diagnosis of schizophrenia, schizotypal and delusional disorders (F20.0 F20.9) or mood disorders (F30 - F33.9) combined with at least one ICD-10 diagnosis of mental and behavioral disorders due to psychoactive substance use (F10-19), ex- 
cluding F17 which is mental and behavioral disorders due to use of tobacco.

Patients who stayed in the ward less than 48 hours, who had a known history of psychosurgery, epilepsy or severe head injury, who needed a foreign language interpreter, who had a history of severe violence or who came from a forensic ward were all excluded, as well as non-consenting patients and patients not fulfilling inclusion criteria. Data with regard to age, gender, psychiatric diagnosis including substance use disorders and reasons for exclusion was collected from excluded patients, except for non-consenting patients.

For the specific sub- analysis of psychiatric diagnostic subgroups and substance use disorders, 24 patients were not included. These patients did not meet precise M.I.N.I. diagnostic criteria as defined in the inclusion criteria for either a specific psychiatric diagnosis $(n=11)$, a specific substance use disorder $(n=12)$ or both $(n=1)$. However, they were included in the overall study group as clinicians confirmed that they were dual diagnosis patients as specified in the inclusion criteria. ISADORA study aimed also to describe pathways through care for people with dual diagnosis and the patients were followed in this respect.

\section{Results}

\section{Sociodemographic sample characteristics}

Table 2 reports the distribution of the sociodemographic characteristics of the patients. No significant difference in age was found between males and females. Comparing the 7 European sites, no significant differences were found with regard to gender. However, sites differed with regard to mean age, educational level, marital status and living arrangements $(\mathrm{p}<0.050)$.

\section{Psychiatric diagnosis}

As seen in table 3, psychosis was the most prevalent psychiatric diagnosis $(40.3 \%)$.

Using chi-squared analysis significant differences were found with regard to psychiatric diagnosis between sites $\left(\mathrm{chi}^{2}=70.618\right.$, $\mathrm{df}=18, \mathrm{p}<0.001)$. Compared to other sites depression was found to be significantly more frequent in Warsaw (37.5\%), bipolar disorder was significantly more frequent in Middlesex and Aarhus (22\% and 20\% respectively) and Tampere (45.1\%) had a significantly higher proportion of patients with mood disorder with psychotic features. Finally, psychosis was significantly more prevalent in Dundee $(55.3 \%)$ and Cambridge $(54 \%)$ than at other sites.

For further analyses the 4 diagnostic groups were organised into two broader categories of psychiatric illness due to few observations within some subgroups: mood disorders (depression, bipolar disorder and mood disorder with psychotic features) and psychotic disorders only.

\section{Substance use disorders}

Table 4 presents different types of substance use disorders across the seven European study sites. Generally, alcohol was the most frequently used substance $(74.1 \%)$. Significant differences were found between sites with regard to non-alcoholic substance use disorder $(\mathrm{p}<0.050)$. In Paris, no patients used stimulants, whereas $24 \%$ of patients in Aarhus were diagnosed with this substance use disorder. Similarly, cannabis use was significantly more prevalent in Middlesex (60\%) than in Warsaw (14\%). 


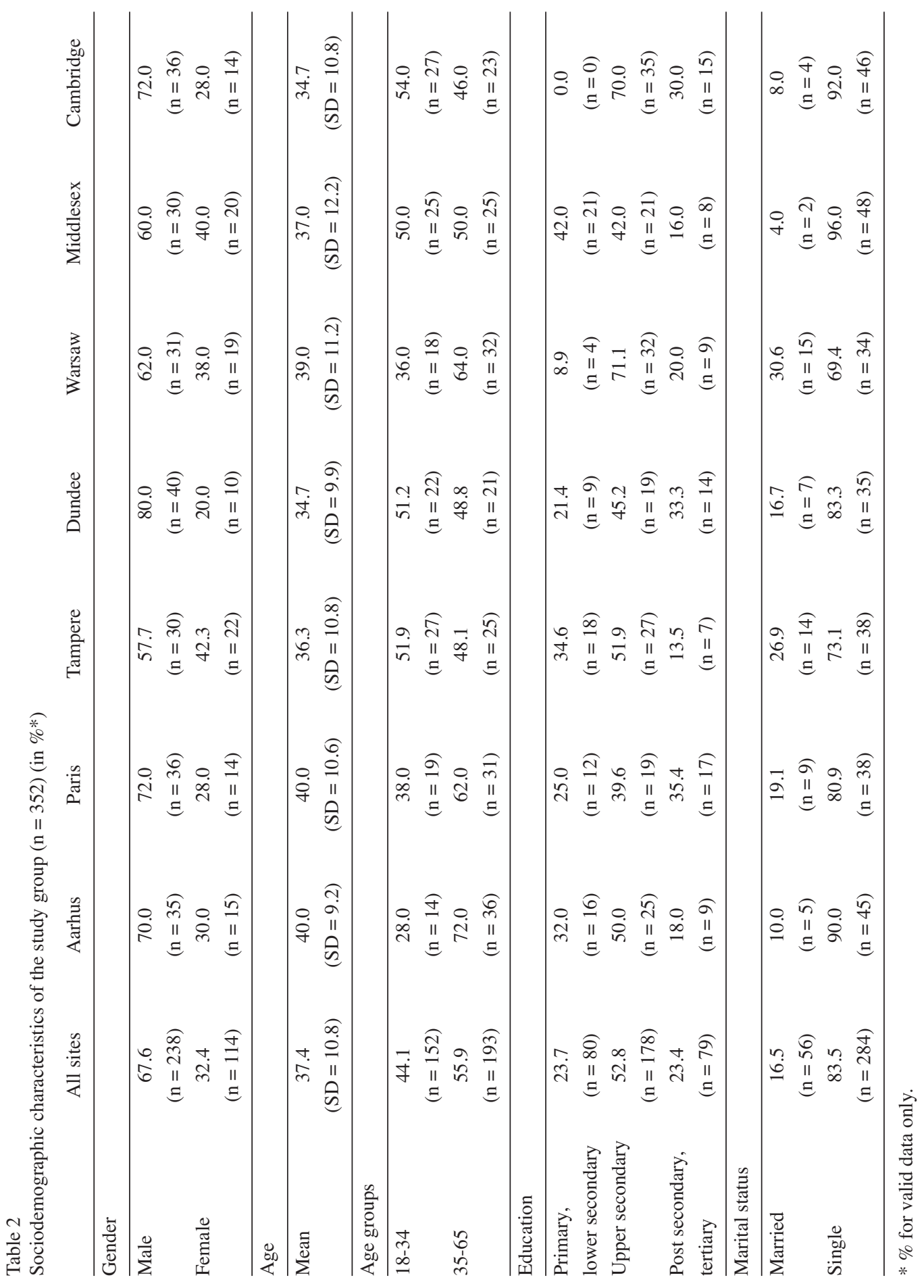




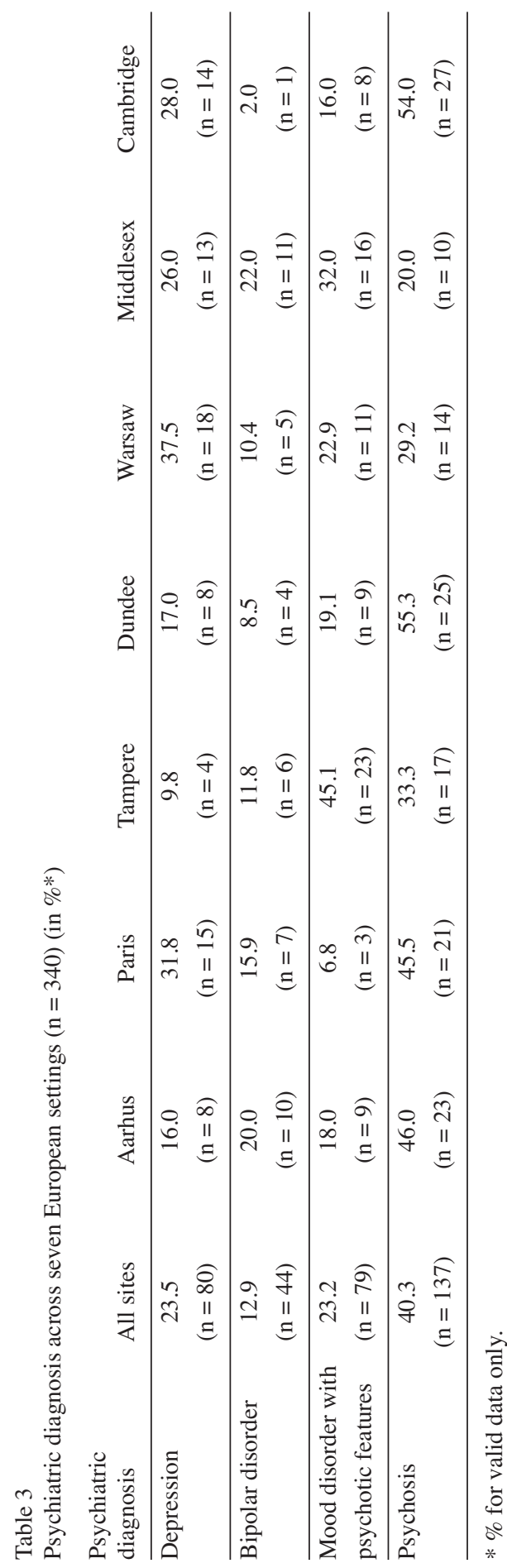

\section{Substance use disorders in psychiatric diagnostic groups}

Alcohol was found to be the most commonly used substance in all M.I.N.I. diagnostic subgroups. In second place across all diagnostic subgroups was cannabis use. However, differences were found with regard to the third most frequently used substance for each diagnostic subgroup: tranquilizers and narcotics (heroin, morphine and methadone) were used by $11.3 \%$ of depressed patients, $18.2 \%$ of psychotic patients used narcotics (heroin, morphine, methadone), 20.5\% of bipolar patients used cocaine and $11.4 \%$ of patients with mood disorder with psychotic features used tranquilizers.

Due to high overlap between different types of substance use disorders $(39.5 \%$ of the sample used two or more psychoactive substances and as many as $8 \%$ used four different substances), for subsequent analyses, data were grouped into 3 broad substance misuse categories: alcohol use disorder, drug use disorders and combined alcohol/drug use disorders. Using this categorization, the most prevalent diagnosis in the sample was alcohol use disorder alone (42.7\%), followed by alcohol/drug use disorders (34.8\%) and drug use disorders alone (22.6\%).

The crosstabs procedure was performed to assess if the prevalence of substance use disorders differed across diagnostic groups (table 5).

Significant differences between psychiatric diagnosis and patterns of substance use disorders were found $\left(\mathrm{chi}^{2}=37.342, \mathrm{df}=8\right.$, $\mathrm{p}<0.001)$. Alcohol misuse alone was the most common pattern in patients with depression and mood disorders with psychotic features $(64.1 \%$ and $50.7 \%$ respectively) whereas use of a combination of alcohol and other substances was the most prevalent pattern among patients with bipolar disorder $(53,7 \%)$ and psychosis $(36.6 \%)$. 


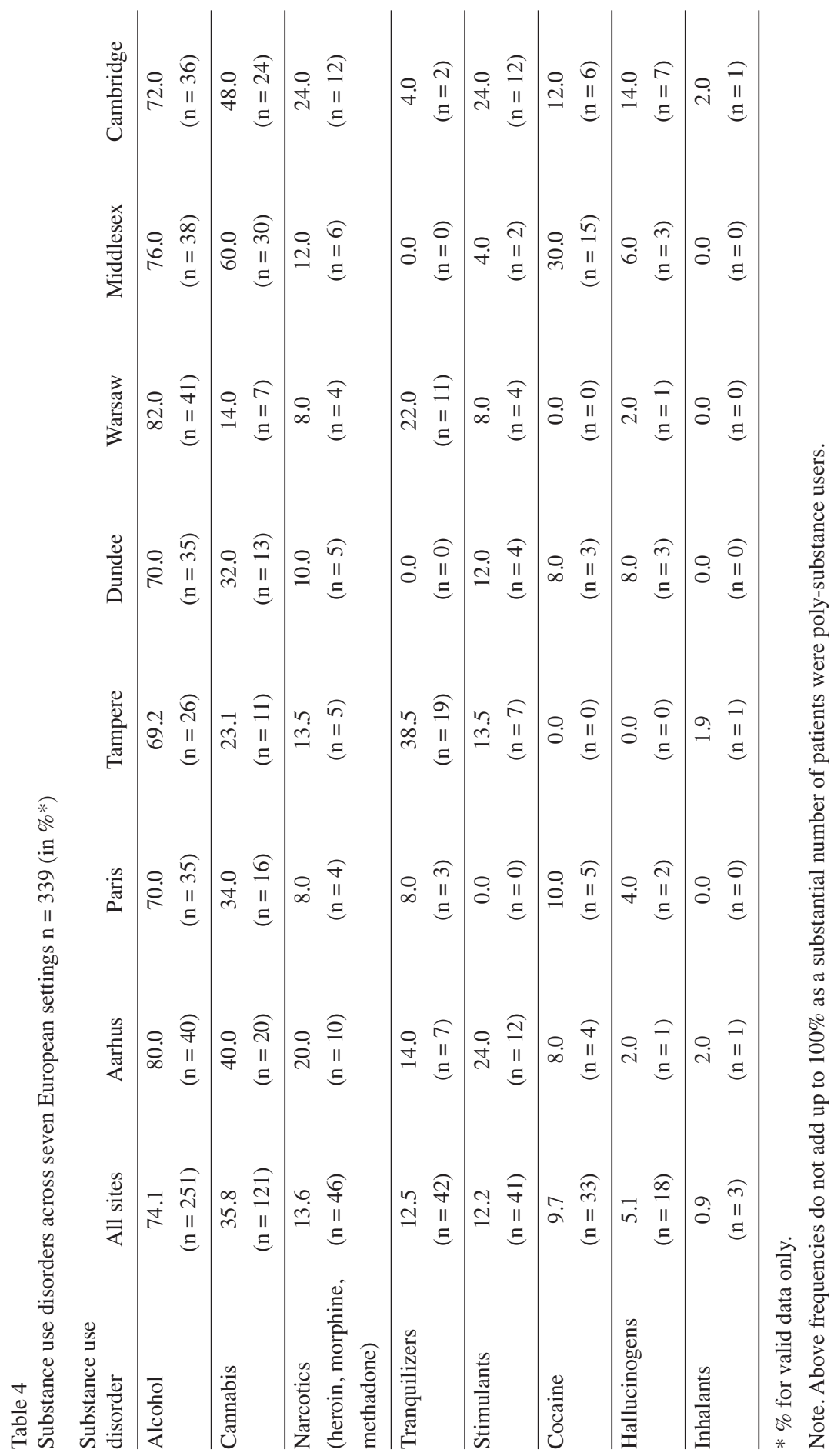


Table 5

Patients with substance use disorders by diagnosis $(\mathrm{n}=328)($ in $\% *)$

Substance use disorder

Total

\begin{tabular}{llcccc}
\hline & Alcohol & Drug & Alcohol + drug & \\
\hline & Depression & $\begin{array}{c}64.1 \\
(\mathrm{n}=51)\end{array}$ & $\begin{array}{c}15.4 \\
(\mathrm{n}=12)\end{array}$ & $\begin{array}{c}20.5 \\
(\mathrm{n}=16)\end{array}$ & $\begin{array}{c}100.0 \\
(\mathrm{n}=79)\end{array}$ \\
\cline { 2 - 6 } & Bipolar disorder & $\begin{array}{c}31.7 \\
(\mathrm{n}=13)\end{array}$ & $\begin{array}{c}14.6 \\
(\mathrm{n}=6)\end{array}$ & $\begin{array}{c}53.7 \\
(\mathrm{n}=23)\end{array}$ & $\begin{array}{c}100.0 \\
(\mathrm{n}=42)\end{array}$ \\
\cline { 2 - 6 } $\begin{array}{l}\text { Psychiatric } \\
\text { diagnosis }\end{array}$ & Mood disorder with & 50.7 & 13.3 & 36.0 & 100.0 \\
& psychotic features & $(\mathrm{n}=37)$ & $(\mathrm{n}=10)$ & $(\mathrm{n}=26)$ & $(\mathrm{n}=73)$ \\
\cline { 2 - 6 } & Psychosis & 29.1 & 34.3 & 36.6 & 100.0 \\
& Total & $(\mathrm{n}=39)$ & $(\mathrm{n}=46)$ & $(\mathrm{n}=49)$ & $(\mathrm{n}=134)$ \\
\hline & $\begin{array}{c}42.7 \\
(\mathrm{n}=140)\end{array}$ & $\begin{array}{c}22.6 \\
(\mathrm{n}=74)\end{array}$ & $\begin{array}{c}34.8 \\
(\mathrm{n}=114)\end{array}$ & $\begin{array}{c}100.0 \\
(\mathrm{n}=328)\end{array}$ \\
\hline
\end{tabular}

* \% for valid data only.

Comorbidity patterns in dual diagnostic patients and investigations of associations between these patterns and demographic variables

Based upon an assessment of the participants' history of substance use disorder and psychiatric illness, they were allocated to one of the six comorbidity groups (table 6). Comorbidity of alcohol use disorder and mood disorder was the most frequently identified pattern $(30.8 \%)$.

Univariate analyses examining associations between patient characteristics and type of comorbidity pattern are summarized in table 7 . The comorbidity subgroups differed significantly with regard to three variables only: gender, age and site $(\mathrm{p}<0.050)$. With regard to gender, comorbidity of alcohol use disorder and mood disorders was generally found to be more prevalent among

Table 6

Frequency of comorbidity patterns $(n=328)$

\begin{tabular}{llcc} 
& & Frequency & Valid Percent \\
\hline Comorbidity patterns & Alcohol + mood disorder & 101 & 30.8 \\
\hline & Alcohol + psychosis & 39 & 11.9 \\
\hline Drug + mood disorder & 28 & 8.5 \\
\hline Drug + psychosis & 46 & 14.0 \\
\hline Alcohol/drug + mood disorder & 65 & 19.8 \\
\hline Alcohol/drug + psychosis & 49 & 14.9 \\
\hline Total & 328 & 100.0 \\
\hline
\end{tabular}




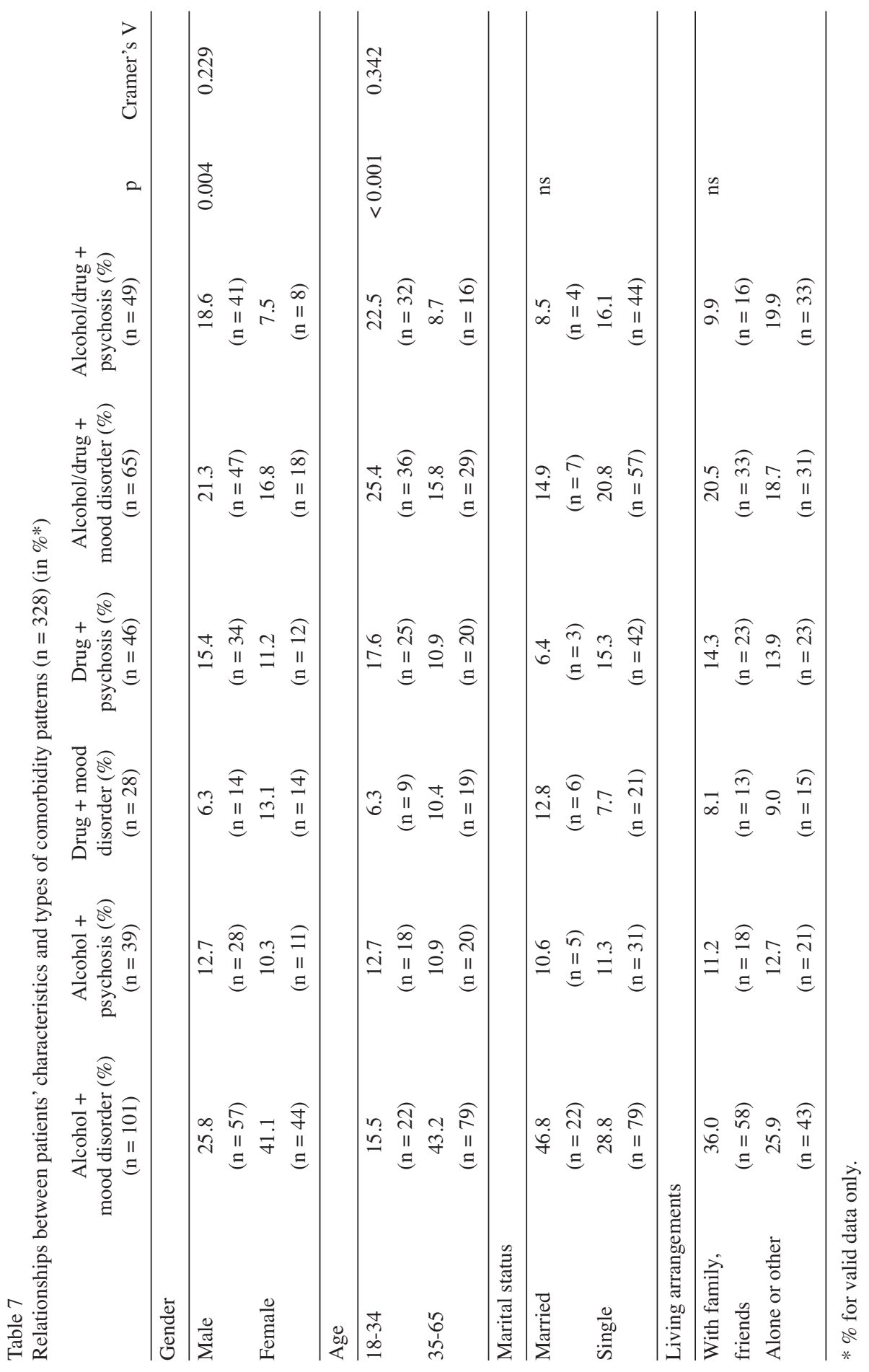




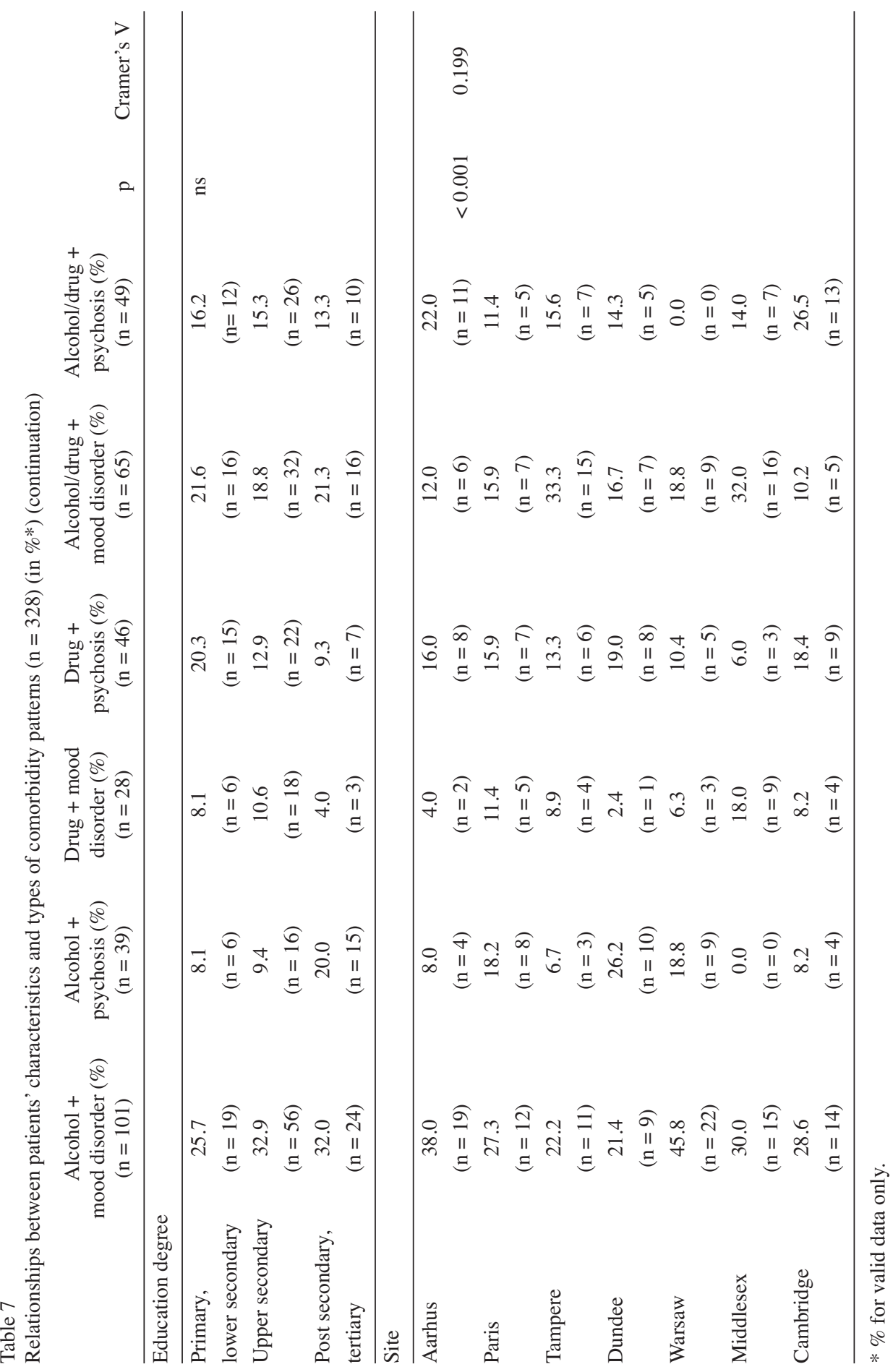


females $(41.1 \%)$ than males $(25.8 \%)$. In contrast, drug/alcohol use disorder combined with psychosis was found significantly more often among males (18.6\%) than females $(7.5 \%)$. With regard to age, comorbidity of alcohol use disorder and mood disorders was most prevalent in the 35-65 age group $(43.2 \%)$. In the younger age group $(<35$ years) drug/alcohol use disorder and mood disorder was the most frequent diagnosis (25.4\%). With regard to site, comorbidity of alcohol use and mood disorder was found to be more frequent in Aarhus and Warsaw than at the other European sites. Alcohol/drug use disorder and mood disorders occurred more frequently in Middlesex and Tampere.

\section{Discussion}

Most studies of dual diagnosis explore prevalence of comorbidity and its characteristics among patients with mental illness. As a result, the current findings concerning prevalence of different types of both substance use disorders and mental illnesses among dual diagnosis patients may differ from those in other studies.

In the present study mood disorder was more frequent than psychotic disorder $(59.6 \%$ and $40.3 \%$, respectively), whereas Graham et al. ${ }^{17}$ showed prevalence rates of $69.6 \%$ and $30.3 \%$ for psychosis and mood disorder respectively.

Similar to other studies ${ }^{2,18}$ alcohol was found to be the most commonly used substance, followed by cannabis. Although in other studies cocaine is reported to be the third most frequently used substance 7,17 , in the present study, narcotics (heroin, morphine and methadone) came in the third place.
The prevalence of alcohol and cannabis use disorder among patients with psychosis (65.7\% and $47.4 \%$, respectively) in this study demonstrates slightly higher rates than in other studies (19). Studies by Grant et al. ${ }^{20}$ and Hasin et al. ${ }^{21}$ show that the ratio of drug use disorders to alcohol use disorders among patients with depression is 0.42 (17\% used drugs and $40 \%$ alcohol). The same ratio value was found in the present study, with $36 \%$ using drugs and $85 \%$ alcohol. For patients with bipolar disorder, the order of the substances most frequently used was consistent with the findings by the Baethge et al. ${ }^{22}$.

As indicated above, due to overlap between different types of substance use disorders, the present sample was divided into 3 subgroups: alcohol disorder only (42.7\%), drug use disorder only $(34.8 \%)$, and alcohol/drug use disorder (22.6\%). Similar prevalence rates in the same diagnostic groups have been observed in other studies ${ }^{10,19}$, with approximately $30 \%$ of the patients with an alcohol use disorder only, $30 \%$ with a drug use disorder only and $30 \%$ with combined alcohol/ drug use disorders.

To the best of our knowledge, no prior studies have used a similar methodology to examine comorbidity patterns within psychiatric inpatients. Thus differences in findings between this and other studies may be due to study methods including recruitment and the nature of the cohort population. In the present study, combined alcohol use disorder and mood disorder was the most prevalent comorbidity pattern $(30.8 \%)$. Furthermore, a combination of mood disorder with either alcohol use disorder or drug use disorder was more common among females and older participants. Meantime, comorbidity of alcohol/drug use disorder with mood disorder and alcohol/drug use disorder with psychosis were more frequent among males 
and in the younger age group. These results are not surprising as males generally are more prone to risk behaviours, including risky use of psychoactive substances. With regard to age, one possible explanation may be that more severe comorbidity patterns may be associated with a higher mortality rate. As a consequence, more severe patterns are less prevalent in older age groups. It is also possible that patterns of substance use evolve with age, with less severe patterns becoming more common with age, or that a generational effect is being observed, with the younger generations having a more severe substance use pattern.

Interesting differences were found across the seven European study sites with regard to different comorbidity patterns. Generally, substance use disorders without concurrent alcohol misuse were less common in Warsaw than at any other site. This is consistent with EMCDDA findings ${ }^{23}$, which revealed that non-alcoholic substances are used less frequently in Poland than in any other country participating in the ISADORA study.

Concurrent alcohol use disorder and mood disorder was also high at Aarhus whilst Tampere observed lower rates of alcohol use disorder with mood disorder and combined alcohol use disorder and psychosis. Normally, outpatient substance use services in Denmark are separated from psychiatric services. However, this site has an emergency department with extensive services for alcohol detoxification, which no doubt influenced current results. Similarly, in Tampere, the findings may be influenced by the fact that patients with drug use disorders are treated at psychiatric hospitals, whereas people with alcohol use disorder alone generally are guided to out-patient treatment, regardless of their mental health status.
The results of the current study should be interpreted with some caution due to the following limitations. Firstly, comorbidity was assessed within inpatient treatment populations which tend to include more complex cases. Therefore findings are not generalisable to samples within the general dual diagnosis population, in ambulatory services or to those with no contact with the mental health care system. Secondly, given our sample size, some prevalence estimates lack precision. Additionally, limited sample size is a reason for caution. Thirdly, the study compares the prevalence of comorbidity from samples drawn from centers in seven European countries; caution should be exercised when interpreting results, as geographic variation has been found when comparing samples from the seven sites with regard to age, education, marital status and living arrangements.

The present study provides clinically relevant information on patterns of substance abuse in patients with severe mental illness in Europe. Results underline the need to understand this population and acknowledge the heterogeneous nature of their presentation. Further studies are needed to help us understand the nature of such condition and its appropriate treatment modalities that are individually based and biopsyhosocial in approach.

\section{Acknowledgements}

The Integrated Services Aimed at Dual Diagnosis and Optimal Recovery from Addiction (ISADORA) study was supported by the European Commission, the Fith Framework Programme, Cordis FP5 (Project QLG4-CT-2002-00911). 


\section{References}

1. Regier DA, Farmer ME, Rae DS, Locke BZ, Keith SJ, Judd LL, et al. Comorbidity of mental disorders with alcohol and other drug abuse. Results from the Epidemiologic Catchment Area ECA Study. JAMA 1990; 264(19): 2511-2518.

2. Menezes PR, Johnson S, Thornicroft G, Marshall J, Prosser D, Bebbington P, et al. Drug and alcohol problems among individuals with severe mental illness in south London. Br J Psychiatry 1996; 168(5): 612-619.

3. Hansen SS. Substance use disorders among hospitalized patients in Denmark. Dan Med Bull 2000; 47(3): 232.

4. Lehman AF, Myers CP, Corty E, Thompson JW. Prevalence and patterns of "dual diagnosis" among psychiatric inpatients. Compr Psychiatry 1994; 35(2): 106-112.

5. Wright S, Gournay K, Glorney E, Thornicroft G. Dual diagnosis in the suburbs: prevalence, need, and in-patient service use. Soc Psychiatry Psychiatr Epidemiol 2000; 35(7): 297-304.

6. Dixon L, Haas G, Weiden PJ, Sweeney J, Frances AJ. Drug abuse in schizophrenic patients. Clinical correlates and reasons for use. Am J Psychiatry 1991; 148(2): 224-230.

7. Chen C, Balogh M, Bathija J, Howanitz E, Plutchik $\mathrm{R}$, Conte HR. Substance abuse among psychiatric inpatients. Compr Psychiatry 1992; 33(1): 60-64.

8. Burns L, Teesson M. Alcohol use disorders comorbid with anxiety, depression and drug use disorders. Findings from the Australian National Survey of Mental Health and Well Being. Drug Alcohol Depend 2002; 68(3): 299-307.

9. Drake RE, Wallach MA, Teague GB, Freeman DH, Paskus TS, Clark TA. Housing instability and homelessness among rural schizophrenic patients. Am J Psychiatry 1991; 148(3): 330-336.

10. Weaver T, Rutter D, Madden P, Ward J, Stimson G, Renton A. Results of a screening survey for co-morbid substance misuse amongst patients in treatment for psychotic disorders: prevalence and service needs in an inner London borough. Soc Psychiatry Psychiatr Epidemiol 2001; 36(8): 399-406.

11. Linszen DH, Dingemans PM, Lenior ME. Cannabis abuse and the course of recent-onset schizophrenic disorders. Arch Gen Psychiatry 1994; 51(4): 273-279.

12. Osher FC, Drake RE, Noordsy DL, Teague GB, Hurlbut SC, Biesanz JC, et al. Correlates and outcomes of alcohol use disorder among rural outpatients with schizophrenia. J Clin Psychiatry 1994; 55(3): 109-113.

13. Bartels SJ, Teague GB, Drake RE, Clark RE, Bush PW, Noordsy DL. Substance abuse in schizophrenia: service utilization and costs. J Nerv Ment Dis 1993; 181(4): 227-232.
14. Mccrone P, Menezes PR, Johnson S, Scott H, Thornicroft G, Marshall J, et al. Service use and costs of people with dual diagnosis in South London. Acta Psychiatr Scand 2000; 101(6): 464-472.

15. Sheehan DV, Lecrubier Y, Sheehan KH, Amorim P, Janavs J, Weiller E, et al. The Mini-International Neuropsychiatric Interview (M.I.N.I): The development and validation of a structured diagnostic psychiatric interview for DSM-IV and ICD-10. J. Clin. Psychiatry 1998; 59(20): 22-33.

16. Mclellan AT, Luborsky L, Woody GE, O'Brien CP. An improved diagnostic evaluation instrument for substance abuse patients. The Addiction Severity Index. J Nerv Ment Dis 1980; 168(1): 26-33.

17. Graham HL, Maslin J, Copello A, Birchwood M, Mueser K, McGovern D, et al. Drug and alcohol problems amongst individuals with severe mental health problems in an inner city area of the UK. Soc Psychiatry Psychiatr Epidemiol 2001; 36(9): 448-455.

18. Graham HL, Maslin J. Problematic cannabis use amongst those with severe mental health problems in an inner city area of the UK. Addict Behav 2002; 27(2): 261-273.

19. Miles H, Johnson S, Amponsah- Afuwape S, Finch E, Leese M, Thornicroft G. Characteristics of subgroups of individuals with psychotic illness and a comorbid substance use disorder. Psychiatr Serv 2003; 54(4): 554-561.

20. Grant BF, Harford TC. Comorbidity between DSM-IV alcohol use disorders and major depression. Results of a national survey. Drug Alcohol Depend 1995; 39(3): 197-206.

21. Hasin DS, Goodwin RD, Stinson FS, Grant BF. Epidemiology of major depressive disorder. Results from the National Epidemiologic Survey on Alcoholism and Related Conditions. Arch Gen Psychiatry 2005; 62(10): 1097-1106.

22. Baethge C, Baldessarini RJ, Khalsa HM, Hennen J, Salvatore P, Tohen M. Substance abuse in first-episode bipolar I disorder: indications for early intervention. Am J Psychiatry 2005; 162(5): 1008-1010.

23. European Monitoring Centre For Drugs And Alcohol Addiction. Annual Report. The state of the drugs problem in Europe. Lisbon: European Monitoring Centre For Drugs And Alcohol Addiction; 2005.

Author for correspondence:

K. Charzynska

Institute of Psychiatry and Neurology

Sobieskiego 9, 02-957 Warsaw

Poland

Phone: +48 602138961 .

Fax: +48 228589172

E-mail: sierk@ipin.edu.pl 